\title{
The methodological quality of animal research in critical care: the public face of science
}

\author{
Meredith Bara ${ }^{1}$ and Ari R Joffe $2^{2^{*}}$
}

\begin{abstract}
Background: Animal research (AR) findings often do not translate to humans; one potential reason is the poor methodological quality of AR. We aimed to determine this quality of AR reported in critical care journals.

Methods: All AR published from January to June 2012 in three high-impact critical care journals were reviewed. A case report form and instruction manual with clear definitions were created, based on published recommendations, including the ARRIVE guidelines. Data were analyzed with descriptive statistics.

Results: Seventy-seven AR publications were reviewed. Our primary outcome (animal strain, sex, and weight or age described) was reported in 52 (68\%; 95\% confidence interval, 56\% to 77\%). Of the 77 publications, 47 (61\%) reported randomization; of these, $3(6 \%)$ reported allocation concealment, and $1(2 \%)$ the randomization procedure. Of the 77 publications, 31 (40\%) reported some type of blinding; of these, disease induction (2, 7\%), intervention (7, 23\%), and/or subjective outcomes (17,55\%) were blinded. A sample size calculation was reported in 4/77 (5\%). Animal numbers were missing in the Methods section in 16 (21\%) publications; when stated, the median was 32 (range 6 to 320; interquartile range, 21 to 70). Extra animals used were mentioned in the Results section in 31 (40\%) publications; this number was unclear in 23 (74\%), and $>100$ for 12 (16\%). When reporting most outcomes, numbers with denominators were given in 35 (45\%), with no unaccounted numbers in 24 (31\%), and no animals excluded from analysis in 20 (26\%). Most (49,64\%) studies reported $>40$, and another $19(25 \%)$ reported 21 to 40 statistical comparisons. Internal validity limitations were discussed in $7(9 \%)$, and external validity (to humans) discussed in 71 (92\%), most with no $(30,42 \%)$ or only a vague $(9,13 \%)$ limitation to this external validity mentioned.
\end{abstract}

Conclusions: The reported methodological quality of AR was poor. Unless the quality of AR significantly improves, the practice may be in serious jeopardy of losing public support.

Keywords: Animal research; Critical care; Intensive care; Methodology

\section{Background}

Translation of biomedical animal research (AR) findings to humans has been disappointing $[1,2]$. There are two main possible reasons for this. First, animals are complex biological systems; their nonlinear dynamics and responses are extremely sensitive to initial conditions $[3,4]$. Despite superficial physiologic and genetic similarity between species, it may not be that responses to similar perturbations or disease will be relevantly similar. Second, the methodological quality of AR may be poor, causing misleading results [5-9]. A third possibility that attempts

\footnotetext{
* Correspondence: ari.joffe@albertahealthservices.ca

${ }^{2}$ Department of Pediatrics, 4-546 Edmonton Clinic Health Academy, University of Alberta, 1140587 Avenue, Edmonton, Alberta T6G 1C9, Canada Full list of author information is available at the end of the article
}

at translation are made prematurely (or badly), before an intervention is well understood, seems less likely to account for failed translation of the many very promising preclinical interventions studied in multiple clinical trials.

The claims made above are supported by much empirical literature. First, the poor translation rate of AR to human medicine has been found in critical care, for example, in the fields of sepsis [10-12], traumatic brain injury [13], resuscitation [14], and spinal cord injury [15]. This has also been found in other highly researched medical fields such as stroke [7], asthma [16], cancer [17], and pharmaceutical drug development [18]. Second, poor methodological quality of AR has been reported in many publications over the past four decades

\section{实}


[5-9,19-26]. The lack of randomization, allocation concealment, blinding, primary outcome and sample size calculation, as well as multiple statistical testing, and publication bias have been assumed to account for the poor translation of AR to human medicine [3,6,8,27]. The ARRIVE guidelines [28], supported by many highimpact journals, and other national guidelines [29-31], suggest inclusion in publications of these methodological factors that are found to be poorly reported. Third, a growing literature suggests that responses to interventions are different in different species due to in principle differences in initial conditions of complex systems (the organism) resulting in different genomic (and hence functional) outcomes [3,4,32-37].

For example, no novel therapy based on AR has been successful in the treatment of sepsis in humans [10-12]. This may be explained by the finding that the genomic responses to different acute inflammatory stresses, including trauma, burns, and endotoxemia/sepsis are highly similar in humans; however, these responses are not reproduced in mouse models [32]. Among genes changed significantly in humans in these diseases, 'the murine orthologs are close to random in matching their human counterparts' [32]. Indeed, lethal toxicity to bacterial lipopolysaccharide varies almost 10,000-fold in different species [38]. Interestingly, of 120 essential human genes with mouse orthologs, 17 (22.5\%) were nonessential in mice, suggesting that it is possible that mouse models of a large number of human diseases will not yield sufficiently accurate information [36]'. Compatible with this, the ENCODE project suggests that over $80 \%$ of the genome is functionally important for gene expression; it is likely there are 'critical sequence changes in the newly identified regulatory elements that drive functional differences between humans and other species [37]'. This may also explain 'the specific organ biology [from lineage-specific gene expression switches] of various mammals [35]'. These, and other similar findings, suggest that a systems biology approach to the nonlinear complex chaotic dynamics of mammalian organisms in which responses are extremely sensitive to initial conditions (the genome and its epigenetic regulatory mechanisms) explains the lack of translation. By this explanation, in principle, AR findings will not predict human responses.

One step in settling this debate in critical care AR is to determine the most current methodological quality of the relevant AR. To address this, we aimed to determine the reported methodological quality in critical care AR published in the year 2012. We find that the reported methodological quality of AR published in three highimpact critical care journals during 6 months of the year 2012 was poor, potentially contributing to the poor translation rate to human medicine.

\section{Methods}

\section{Ethics statement}

The University of Alberta Health Research Ethics Board waived the requirement for review because the study involved only publicly available data.

We reviewed all consecutive AR published in three prominent critical care journals (Critical Care Medicine, Intensive Care Medicine, and American Journal of Respiratory and Critical Care Medicine) during 6 months of the year 2012 to determine the reporting of a priori-determined methodological quality factors. There were no restrictions other than that the study reported an AR experiment, defined as a procedure for collecting scientific data on the response to an intervention in a systematic way to maximize the chance of answering a question correctly or to provide material for the generation of new hypotheses [26]. Both authors hand-searched and screened the titles and abstracts of all publications in the three journals over the 6 months, and if possibly a report of an AR experiment, the full text was reviewed. If there was any doubt about the inclusion, this was discussed among the two authors to achieve consensus. A data collection form and instruction manual (see Additional files 1 and 2) were created based on published Canadian, US, and UK recommendations for reporting AR [28-31]. These guidelines were used as they are comprehensive, well referenced, readily available, and based upon literature review. For example, the ARRIVE guidelines were developed to improve the quality of reporting AR and are endorsed by over 100 journals from all over the world [28]. Data were obtained for factors important to methodological quality. We also reviewed these publications to determine the reporting of a priori-determined ethical quality factors and have reported this elsewhere [39]. From inception, we considered the ethical and methodological quality as separate issues and decided that reporting them separately was needed to adequately report each issue and discuss its implications.

The form was completed for all consecutive critical care AR (using mammals) publications (including all supplemental files online) from January to June 2012 in the three critical care journals. Both authors independently completed forms for the first 25 papers, discussing the data after every fifth form until consistent agreement was obtained. Thereafter, one author completed forms on all papers, and the other author independently did so for every fourth paper (with discussion of the data to maintain consistent agreement) and for any data considered uncertain (with discussion until consensus). The instruction manual made clear definitions for all data collection; for example, a sample size calculation was defined as describing, for the primary outcome, a $p$ value (alpha), power (1-beta), and minimally important difference (the difference between groups that the study is powered to detect). 


\section{Statistics}

This is an exploratory descriptive study. Data are presented using descriptive statistics and were analyzed using SPSS. The primary outcome was pre-specified as the composite of reporting the three animal characteristics of strain, sex, and weight or age. In the largest previous survey of AR (not limited to critical care, reviewing publications from 1999 to 2005, and leading to the ARRIVE guidelines), this composite outcome was the primary outcome and reported in only 59\% (159/271) of publications [5]. These variables are important to report to allow replication of AR, and poor replicability of AR results has been a major problem in recent literature $[40,41]$. Our study was designed to determine a reasonable $95 \%$ confidence interval $(\mathrm{CI})$ for this primary outcome. Assuming a similar reporting rate of $59 \%$ to have an adjusted Wald $95 \%$ CI of $\pm 11 \%$, we pre-specified a sample size of 75 publications. Pre-defined subgroups by journal, sepsis model, and animal age (neonate, juvenile, adult) were compared using the Chi-square statistic, with statistical significance accepted at $p<0.05$, without correction for multiple comparisons. Post hoc we identified another subgroup of rodent/rabbit versus nonrodent/nonrabbit models to determine whether more advanced species had improved attention to the methodological quality of AR. We also determined three post hoc composite outcomes: (a) reporting of randomization and any blinding and numbers given with denominators for most outcomes; (b) reporting of the criteria mentioned in (a) and also meeting our pre-defined primary outcome of animal descriptors; and (c) reporting of the criteria mentioned in (b) and also having reported allocation concealment, blinding of subjective outcomes, and no unaccounted animal numbers for most outcomes.

\section{Results}

Results from the review of 77 AR publications (Additional file 3) in three critical care journals are in Tables 1, 2, 3, 4 and 5. For ease of reporting the results, we divide the reporting into the specific sections of the publications; however, if the variable of interest was reported anywhere in the manuscript, we considered it as having been reported.

\section{Our primary outcome (animal descriptors)}

Animal strain, sex, and weight or age were reported in 52 (68\%; $95 \% \mathrm{CI}, 56 \%$ to $77 \%$ ) of publications.

\section{Reporting in the methods section}

In the 47 (61\%) studies reporting randomization, the randomization method $(1,2 \%)$ and allocation concealment $(3,6 \%)$ were rarely reported (Table 1$)$. A minority of studies reported blinding $(31,40 \%)$, and this included for subjective outcomes $(17 / 31,55 \%)$. Reporting a sample size
Table 1 Reported methodological quality of animal research published in three critical care journals in 2012: Methods section

\begin{tabular}{|c|c|}
\hline Criterion & $\begin{array}{l}\text { Number of } 77 \text { publications } \\
\text { meeting criterion, } \boldsymbol{n}(\%) \\
\text { [95\% confidence interval] }\end{array}$ \\
\hline Randomization reported & $47(61 \%)[50 \%, 71 \%]$ \\
\hline Allocation concealment mentioned & $3(6 \%$ of 47$)[2 \%, 18 \%]$ \\
\hline Randomization procedure described & $1(2 \%$ of 47$)[<1 \%, 12 \%]$ \\
\hline $\begin{array}{l}\text { Reported blinding of any type } \\
\text { mentioned below }\end{array}$ & $31(40 \%)[30 \%, 51 \%]$ \\
\hline Disease induction & $14(45 \%$ of 31$)[29 \%, 62 \%]$ \\
\hline Intervention & 7 (23\% of 31$)[11 \%, 40 \%]$ \\
\hline Subjective outcomes & 17 (55\% of 31$)$ [38\%, 71\%] \\
\hline Primary outcome specified & 5 (7\%) $[2 \%, 15 \%]$ \\
\hline Sample size calculation reported & $4(5 \%)[2 \%, 13 \%]$ \\
\hline $\begin{array}{l}\text { More than } 10 \text { secondary outcomes } \\
\text { specified }\end{array}$ & 74 (96\%) [89\%, 99\%] \\
\hline Eligibility criteria for animals stated & $4(5 \%)[2 \%, 13 \%]$ \\
\hline $\begin{array}{l}\text { Acclimation/habituation prior to } \\
\text { experiments stated }\end{array}$ & $6(8 \%)[3 \%, 16 \%]$ \\
\hline $\begin{array}{l}\text { Staff (number or training) performing } \\
\text { experiment described }\end{array}$ & $1(1 \%)[<1 \%, 8 \%]$ \\
\hline $\begin{array}{l}\text { Animal numbers stated in methods } \\
\text { section }\end{array}$ & $61(79 \%)[69 \%, 87 \%]$ \\
\hline Animal numbers (when stated) & $\begin{array}{l}\text { Median } 32 \text { (range } 6 \text { to } 320 \text {; } \\
\text { IQR } 21 \text { to } 70 \text { ) }\end{array}$ \\
\hline $\begin{array}{l}\text { Sepsis model: with any supportive } \\
\text { therapy mentioned }^{a}\end{array}$ & $12(44 \%$ of 27$)[28 \%, 63 \%]$ \\
\hline
\end{tabular}

${ }^{a}$ Sepsis supportive therapies were fluids, 11 (41\% of 27) and antibiotics, 4 (15\% of 27 ). Another 1 (4\% of 27 ) had animals with the co-morbid illness of trauma. The intervention was given only pre-sepsis induction in 7 ( $26 \%$ of 27 ). $\mathrm{IQR}$, interquartile range.

calculation $(4,5 \%)$ and specifying a primary outcome $(5,7 \%)$ were almost never done. Animal numbers were often not reported; animal numbers were given in 61 (70\%) and when stated were a median of $n=32$ (interquartile range 21 to 70, range 6 to 320). Eligibility criteria (inclusion and exclusion) for animals were reported in only 4 (5\%).

\section{Reporting in the results section (animal descriptions)}

Species, strain, and sex were usually described (77, $100 \%$; 67, 87\%; and 59, 77\%, respectively); however, age (29, 38\%), developmental stage (27, 35\%), and description of baseline characteristics in treatment groups (23, 31\%) were often missing (Table 2).

\section{Reporting in the results section (outcomes)}

Extra (31, 40\%), unaccounted for (53, 69\%), and excluded animals (57, 74\%) were common. Extra animals were defined as follows: the number of animals used in the Results section is different from and higher than that stated in Methods section. Unaccounted for animals was 
Table 2 Reported methodological quality of animal research published in three critical care journals in 2012: Results section

\begin{tabular}{ll}
\hline Criterion & $\begin{array}{l}\text { Number of } 77 \text { publications } \\
\text { meeting criterion, } \boldsymbol{n}(\%) \\
\text { [95\% confidence interval] }\end{array}$
\end{tabular}

Animal descriptions reported

Strain
Sex
Age
Developmental stage
Developmental stage when given
Weight
Animal source ${ }^{\text {a }}$
Baseline characteristics of treatment
groups described
Outcomes reported

Number of animals in largest treatment group 10 or less

Extra animals used in the results (that were not stated in methods)

67 (87\%) [78\%, 93\%]

59 (77\%) [66\%, 85\%]

29 (38\%) [28\%, 49\%]

27 (35\%) [25\%, 46\%]

Neonate 5 , juvenile 1 , adult 21

$60(78 \%)[67 \%, 86 \%]$

$33(43 \%)[32 \%, 54 \%]$

$23(31 \%)[21 \%, 41 \%]$

$61(79 \%)[69 \%, 87 \%]$

$31(40 \%)[30 \%, 51 \%]$

Number of extra animals unclear

Number of extra animals $>100$

Numbers with denominators given when reporting the majority of outcomes ${ }^{c}$

No unaccounted animal numbers for the majority of outcomes

No animals excluded from analysis for the majority of outcomes ${ }^{d}$

Animal numbers provided in the majority of tables/graphs

23 (74\% of 31) [57\%, 87\%]

12 (39\% of 31$)[24 \%, 56 \%]$

35 (45\%) [35\%, 57\%]

$24(31 \%)[22 \%, 42 \%]$

$20(26 \%)[17 \%, 37 \%]$

46 (60\%) [49\%, 70\%]

Number of statistical comparisons reported

$\begin{array}{ll}>40 & 49(64 \%)[52 \%, 74 \%] \\ 21 \text { to } 40 & 19(25 \%)[16 \%, 35 \%] \\ 5 \text { to } 20 & 9(12 \%)[6 \%, 21 \%] \\ \begin{array}{l}\text { Any negative outcome reported in } \\ \text { results }\end{array} & 15(20 \%)[12 \%, 30 \%] \\ \begin{array}{l}\text { If applicable, toxicity or lack of } \\ \text { toxicity to animals was mentioned }\end{array} & 11(22 \% \text { of } 49)[13 \%, 36 \%] \\ \text { No post hoc outcomes analyzed } & \end{array}$

${ }^{a}$ Animal sources were commercial, 29 (85\% of 34$)$ and local, 5 (15\% of 34); ${ }^{\mathrm{b}}$ baseline characteristics described were at least two demographic variables 1 (4\% of 24 ) and at least two physiologic variables 19 (79\% of 24$)$; ${ }^{c}$ for the AR articles' primary outcome (specified in five studies): numbers with denominators reported for $3(60 \%$ of 5$)$, no unaccounted numbers for $3(60 \%$ of 5), and numbers in tables/graphs provided in $3\left(60 \%\right.$ of 5); ${ }^{d}$ when some animals were excluded from most analyses, the number excluded $(10,18 \%$ of $57)$ and reasons $(11,19 \%$ of 57$)$ were reported infrequently. For the $A R$ articles' primary outcome, an intention to treat analysis was used for 2 (40\% of 5); ${ }^{\text {f }}$ or the AR articles' primary outcome, a negative result was reported in 0 ( $0 \%$ of 5); ${ }^{f}$ number of post hoc outcomes: none in $40(52 \%$ of 77$),<5$ in 25 ( $32 \%$ of 77$), 5$ to 10 in 8 (10\% of 77$)$, and $>10$ in 4 (5\% of 77$)$.
Table 3 Reported methodological quality of animal research published in three critical care journals in 2012: Discussion section

\begin{tabular}{ll}
\hline Criterion & $\begin{array}{l}\text { Number of 77 publications } \\
\text { meeting criterion, } \boldsymbol{n} \text { (\%) } \\
\text { [95\% confidence interval] }\end{array}$ \\
\hline $\begin{array}{l}\text { Internal validity limitations discussed } \\
\text { External validity (to humans) discussed }\end{array}$ & $7(9 \%)[4 \%, 18 \%]$ \\
$\begin{array}{l}\text { When discussed, no limitation to } \\
\text { external validity (to humans) } \\
\text { mentioned }\end{array}$ & $30(42 \%$ of 71$)[31 \%, 54 \%]$ \\
$\begin{array}{l}\text { When discussed, only a vague } \\
\text { limitation to external validity } \\
\text { mentioned }\end{array}$ & $9(13 \%$ of 71$)[7 \%, 23 \%]$ \\
\hline
\end{tabular}

Internal validity limitations: sample size in 5, methodological bias in 3, and multiple statistical comparisons in 1.

defined as follows: the number of animals used in most analyses was lesser than the number given in the Methods section for unclear reasons. Excluded animals were defined as follows: animals that were stated to be used in the experiments were excluded from the majority of analyses. Outcomes were often reported without denominators in text and tables/graphs (31, 40\%). Most studies performed $>40$ statistical analyses $(49,64 \%)$, often of post hoc outcomes $(37,48 \%)$, with mention of negative (15, $20 \%$ ) or toxicity (applicable if a drug was being studied; $11 / 49,22 \%$ ) outcomes uncommon (Table 2).

\section{The discussion section}

Internal validity limitations were rarely discussed (7, 9\%). External validity (to humans) was mentioned in 71 (92\%); however, limitations to this external validity were often not mentioned (32/71, 45\%) (Table 3).

Table 4 Reported methodological quality of animal research published in three critical care journals in 2012: primary and composite outcomes

\begin{tabular}{|c|c|}
\hline Criterion & $\begin{array}{l}\text { Number of } 77 \text { publications } \\
\text { meeting criterion, } n(\%) \\
\text { [95\% confidence interval] }\end{array}$ \\
\hline \multicolumn{2}{|l|}{ This study's pre-defined primary outcome } \\
\hline $\begin{array}{l}\text { Animal strain, sex, and weight or age } \\
\text { described }\end{array}$ & $52(68 \%)[56 \%, 77 \%]$ \\
\hline \multicolumn{2}{|l|}{ Composite quality outcomes } \\
\hline $\begin{array}{l}\text { Reported randomization and any } \\
\text { blinding, and numbers given with } \\
\text { denominators for the majority of } \\
\text { outcomes }\end{array}$ & $14(18 \%)[11 \%, 28 \%]$ \\
\hline $\begin{array}{l}\text { Criteria above and meeting this } \\
\text { study's pre-defined primary outcome } \\
\text { of animal descriptors }\end{array}$ & $8(10 \%)[5 \%, 19 \%]$ \\
\hline $\begin{array}{l}\text { Criteria above and reporting of } \\
\text { allocation concealment, blinding of } \\
\text { subjective outcomes, and no } \\
\text { unaccounted animal numbers for } \\
\text { the majority of outcomes }\end{array}$ & $0(0 \%)[0 \%, 4 \%]$ \\
\hline
\end{tabular}


Table 5 Methodological quality of animal research published in three critical care journals: rodent/rabbit versus nonrodent/nonrabbit subgroup

\begin{tabular}{|c|c|c|c|}
\hline \multirow[t]{2}{*}{ Criterion } & \multicolumn{3}{|c|}{ Number of publications meeting criterion; $\boldsymbol{n}(\%)[95 \% \mathrm{Cl}]$} \\
\hline & Rodent/rabbit $(n=54)$ & Nonrodent/nonrabbit $(n=23)$ & $p$ value \\
\hline \multicolumn{4}{|l|}{ This study's pre-defined primary outcome } \\
\hline Animal strain, sex, and weight or age described & 45 (83\%) [71\%, 91\%] & 7 (30\%) [15\%, 51\%] & $<0.001$ \\
\hline \multicolumn{4}{|l|}{ Methods } \\
\hline Animal numbers stated in methods & $35(65 \%)[51 \%, 76 \%]$ & $21(91 \%)[72 \%, 99 \%]$ & 0.049 \\
\hline Reporting randomization & $25(46 \%)[34 \%, 59 \%]$ & $22(96 \%)[77 \%,>99 \%]$ & $<0.001$ \\
\hline \multicolumn{4}{|l|}{ Results: animal descriptions reported } \\
\hline Sex & $48(89 \%)[77 \%, 95 \%]$ & $11(48 \%)[29 \%, 67 \%]$ & $<0.001$ \\
\hline Weight & $38(70 \%)[57 \%, 81 \%]$ & $22(96 \%)[77 \%,>99 \%]$ & 0.011 \\
\hline Source & $30(56 \%)[42 \%, 68 \%]$ & $3(13 \%)[4 \%, 33 \%]$ & $<0.001$ \\
\hline \multicolumn{4}{|l|}{ Results: outcomes reported } \\
\hline Extra animals used in the results (that were not stated in methods) & $27(50 \%)[37 \%, 63 \%]$ & $4(17 \%)[6 \%, 38 \%]$ & 0.007 \\
\hline Animal numbers in the majority of tables and graphs & $37(69 \%)[55 \%, 79 \%]$ & $9(39 \%)[22 \%, 59 \%]$ & 0.016 \\
\hline Baseline characteristics of treatment groups described & $9(17 \%)[9 \%, 29 \%]$ & 15 (65\%) [45\%, 81\%] & $<0.001$ \\
\hline \multicolumn{4}{|l|}{ Discussion } \\
\hline Limitation to external validity (to humans) mentioned & 16 (33\%) [19\%, 43\%] & $16(70 \%)[49 \%, 85 \%]$ & 0.002 \\
\hline \multicolumn{4}{|l|}{ Composite quality outcomes } \\
\hline $\begin{array}{l}\text { Reporting randomization and any blinding, and numbers given with } \\
\text { denominators for the majority of outcomes }\end{array}$ & $10(19 \%)[10 \%, 31 \%]$ & $4(17 \%)[6 \%, 38 \%]$ & ns \\
\hline Criteria above and meeting this study's pre-defined primary outcome & $8(15 \%)[7 \%, 27 \%]$ & $0(0 \%)[0 \%, 13 \%]$ & ns \\
\hline
\end{tabular}

Animals in the publications were nonrodent/nonrabbit- baboon (1), dog (3), pig (17), sheep (2); rodent/rabbit- mouse (17), rabbit (5), and rat (32). There were no statistically significant differences between these subgroups in any of the other methodological criteria shown in Tables 1, 2, 3 and 4 . ns, not significant.

\section{Composite outcomes}

Fourteen (18\%) met the composite outcome of reporting any randomization, any blinding, and numbers given with denominators for most outcomes; only 8 (10\%) met the composite outcome of the aforementioned criteria and adding meeting our primary outcome of animal descriptors (Table 4).

\section{Funding sources}

Funding source was reported for 69 (90\%) of the publications. Most studies were funded using public dollars, either from government $(51 / 69,74 \%)$ and/or foundation/ charity $(34 / 69,49 \%)$; industry funding was uncommon $(11 / 69,16 \%)$.

\section{Subgroups}

Sepsis models $(n=27)$ and studies in the higher-impact journal were lower in quality (less often reporting randomization, stating animal numbers in the Methods section, and reporting animal weight; all $p \leq 0.004$ ). Adult animal studies more often reported sex and our primary outcome of animal descriptors $(p<0.01)$. The post hoc subgroup of nonrodent/nonrabbit (vs. rodent/ rabbit) AR showed few differences in quality practices (Table 5). The nonrodent/nonrabbit publications more often compared baseline characteristics of treatment groups and mentioned limitation to external validity; they less often had extra animals used in the results that were not mentioned in the Methods. However, they have more often missing animal numbers in most tables/graphs and did not have better reporting of the composite quality outcomes.

\section{Discussion}

The reported methodological quality of $A R$ in three high-impact critical care journals during 6 months of 2012 was poor. This is important for several reasons. First, poor attention to reporting optimal methodology in AR confounds the interpretation and extrapolation of experimental results [5,27-31]. Thus, attention to reporting methodological quality is necessary to performing reliable quality research. Second, the interests of sentient animals in avoiding harm ought to be given more consideration in the reporting of AR $[42,43]$. The ethical justification of biomedical AR that can harm animals (by any associated distress and death) usually includes reference to its necessity for producing large benefits to human medicine $[1,2,44]$. Thus, this ethical justification of AR assumes the reporting of high-quality research necessary to produce these benefits $[1,2,6,45]$. Third, attempted 
translation to humans from methodologically weak AR unnecessarily puts humans at risk and wastes scarce research resources. Fourth, these publications are, arguably, the public face of science using mostly public funds. Unless the methodological quality of AR reporting improves, $\mathrm{AR}$ is at risk of losing public support. Recent surveys suggest public support for AR is based on the assumption that attention to the $3 \mathrm{Rs}$ (refinement, reduction, replacement) is a priority; public support for AR is far from universal and may be tenuous [46-48].

We reported separately the ethical quality of the same AR publications examined here and found that it was poor [39]. Few publications $(5 / 71,7 \%)$ reported monitoring the level of anesthesia during invasive procedures, even when muscle paralytics were used (2/12, 17\%). Few publications reported monitoring $(2 / 49,4 \%)$ or treatment $(7 / 49,14 \%)$ of expected pain. When euthanasia was used, the method was reported for 38/65 (59\%) of publications; in these, euthanasia was reported to be of an acceptable or justified conditionally acceptable method for the species in 16/38 (42\%). [39]. This adds to the problem of translation from AR to humans because pain and distress cause changes in physiology, immunology, and behavior that confound interpretation and extrapolation of experimental results $[49,50]$.

Limitations of this study include the limited sample size of publications reviewed, the limited scope to critical care AR, and the low power to detect differences between subgroups particularly given multiple comparisons. We did not determine inter-rater reliability of data extraction, and it is possible that our methods of ensuring consistent agreement were insufficient. Finally, our composite outcomes were defined post hoc, and although they give a general idea of the way AR reported several quality criteria in the same study, they should be interpreted with caution. Nonetheless, this study is the first to focus on AR in critical care and reviewed a reasonable number of consecutive publications in three high-impact critical care journals using an objective data collection form and instruction manual. Whether our findings from this critical care AR cohort generalize to most AR is unknown; however, we believe this is likely because many others have reported similar findings in other AR fields in the past [5-9,19-25].

Another limitation is that we only describe reporting of the quality items; it may very well be that what was not reported was actually done. Thus, it is possible that the methodological quality of the AR was good, and only the reporting was poor. This explanation is problematic for several reasons. First, many of these quality items might have been expected to be reported if they were indeed performed. For example, if a sample size calculation for a pre-specified primary outcome, including a $p$ value, power, and minimally important difference, was calculated, the authors would plausibly be expected to report this knowing that it would markedly improve the quality of their experimental result. Optimal methods of randomization, allocation concealment, and blinding may be difficult, time consuming, and expensive to implement, and are known to strengthen the importance and validity of a study; this makes it implausible that these would not be reported if they were done [6,19-22]. Second, many of the quality items we found missing are necessary for readers to adequately evaluate the internal and external validity of the study and to understand and be able to reproduce the methods and results [28-31]. For example, the strain, sex, age, weight, source, and baseline characteristics of animals are important potentially confounding variables in a study; understanding research subject numbers and flow are important to understand the methodology and analysis of a study; and multiple statistical testing, particularly with post hoc outcomes, weaken any inferences that can be made from study results [27-31]. Not reporting this information thus makes the published study findings unreliable, regardless of whether the information was in fact known to the authors. Third, that very few studies discussed internal validity limitations suggests that the authors may not recognize the importance of the methodological factors and may not have incorporated them into their study design.

Poorly reported methodological quality of AR has been reported before [19-26]. In fact, the lack of randomization, allocation concealment, blinding, eligibility criteria, primary outcome, and sample size calculation, as well as multiple statistical testing, and publication bias have been assumed to account for the poor translation of AR to human medicine $[3,6,8,27,51]$. In both human and animal research, lack of reporting of these items is associated with overestimation of intervention efficacy [19-22,52,53]. Our findings significantly add to this literature because previous publications have not focused on the entire spectrum of these quality variables, were done before some of the recent guidelines on optimal AR were published, and/or did not focus on critical care AR in particular, as in this study. One other study determined that methodological quality of AR reporting experimental allergic encephalitis models of multiple sclerosis has not improved between 2 years before and 2 years after endorsement of the ARRIVE guidelines [54].

These findings are concerning. The ARRIVE guidelines, supported by many high-impact journals, and other national guidelines, suggest inclusion in publications of the factors that we found to be poorly reported [28-31]. Given the generally poor translation rate of AR to human medicine [6-8,13-18,27,55,56] (e.g., in the field of sepsis, no novel therapy based on AR has been successful in treatment of sepsis in humans) [10-12], researchers should seriously consider whether this is because of lack of sufficient 
attention to methodological quality, including factors we did not assess in this paper, such as publication bias. This is particularly true because one alternative explanation is that biological differences between species make AR in principle, based on complexity science, unable to predict responses in humans. AR where the experimental question is subject to study solely by reductionism, that is, by examining simple systems at a gross level (for example, discovering the germ theory of disease, that the heart circulates blood, and that the immune system reacts to foreign entities), may translate [57]. However, for the details, such as whether the animal model will accurately predict human response to drugs and disease, complexity science suggests an in principle limitation to AR.

It is true that some findings from AR have translated to humans; one example is the use of lower tidal volumes in acute respiratory distress syndrome (ARDS) to limit ventilator-induced lung injury [58]. This may be because the AR these interventions were based on was of higher quality. However, a retrospective look at interventions that successfully translated does not provide a complete picture of the accuracy for translation of an animal model. For example, a recent review of interventions for ARDS found that only two interventions (low tidal volume and prone positioning) from 93 human trials of over 37 interventions had robust evidence of translation, and one was harmful (HFO) [59]. Even for lower tidal volume, there was a question whether this was beneficial when compared to relatively higher tidal volume that limited airway pressures [59]. A systematic review of the AR relating to VILI to examine the methodological quality of studies, assess publication bias, and determine the association of quality with efficacy would be very informative in this debate.

We note that an improved methodological quality will reduce the flexibility in design, definitions, outcomes, and analytical modes in a study and thus improve the reliability of a reported $p$ value (i.e., reduce ' $p$-hacking') $[60,61]$. However, this will not prevent misinterpretation of the $p$ value $[62,63]$. Although it is sometimes thought that $p<0.05$ means that the probability of the null hypothesis is $<5 \%$, this is false. For example, in a human trial with equipoise, the prior probability of the null hypothesis is $50 \%$, and a $p=0.05$ means the probability of the null hypothesis is down to no lower than $13 \%$ [64-66]. The probability of the null hypothesis depends on its prior probability and the Bayes factor (a measure of the likelihood of the null hypothesis after the study evidence, relative to the likelihood before the study) which can be calculated based on the $p$ value [65]. Thus, the $p$ value that reduces the probability of the null hypothesis to no less than $5 \%$ depends on the prior probability of the null hypothesis: $17 \%$ prior probability needs $p=0.10,26 \%$ needs $p=0.05,33 \%$ needs $p=0.03$,
$60 \%$ needs $p=0.01$, and $92 \%$ needs $p=0.001[64,65]$. This has the following implications for AR: the methodological quality must be optimized so that the reported $p$ value is robust; studies should be based on external evidence (mechanistic, observational, clinical) that makes the prior probability of the null hypothesis lower that 50\%; and if an exploratory study is done (where the null hypothesis is likely), it should be followed by a replication study with the same design and outcome (because the null hypothesis has become less likely) [60-65]. The low replication rate of much AR [40,41] suggests that either these methodological issues are at fault, or, that AR will not translate in principle, based on considerations from complexity science.

We believe that a serious debate about the methodological quality of AR in critical care is urgent. Better attention to, and reporting of, methodological factors in AR can only improve the research quality, ethical quality, and public perception of $A R$, and improve the safety of humans in translational research. As we reported elsewhere, improved attention to the ethical dimension of AR can only improve these factors as well [39]. Journal editors and reviewers and funding agencies should use their influence to improve quality reporting of AR they publish and support $[67,68]$. This includes endorsing and enforcing reporting standards, such as the ARRIVE guidelines, and prioritizing and publishing well-conducted negative studies and replication studies in addition to novel positive studies. Editors and funders hold substantial power to improve the quality of AR and reduce publication bias.

\section{Conclusions}

We found that reported methodological quality of AR in three high-impact critical care journals during 6 months of the year 2012 was poor. These findings warrant the attention of clinicians, researchers, journal editors and reviewers, and funding agencies. Improved attention to the reporting of methodological quality by these groups can only improve AR quality and the public perception of AR.

\section{Additional files}

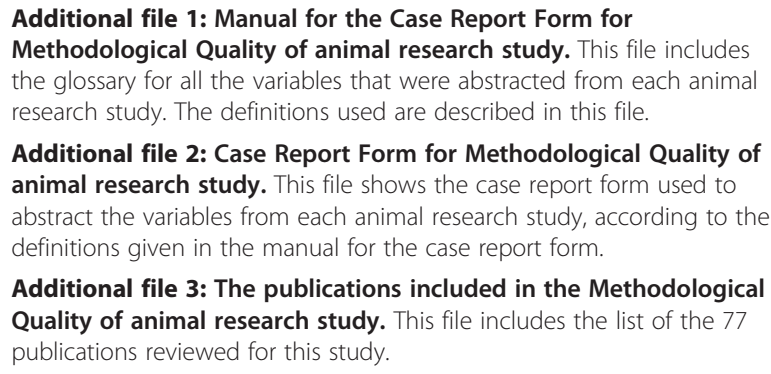

Additional file 2: Case Report Form for Methodological Quality of animal research study. This file shows the case report form used to abstract the variables from each animal research study, according to the definitions given in the manual for the case report form.

Additional file 3: The publications included in the Methodological Quality of animal research study. This file includes the list of the 77 publications reviewed for this study.

\section{Competing interests}

The authors declare that they have no competing interests. 


\section{Authors' contributions}

ARJ contributed to conception and design, acquisition of data, analysis and interpretation of data, and drafted the article. MB contributed to design, acquisition of data and interpretation of data, revising the article critically for important intellectual content. ARJ had full access to all the data in the study and takes responsibility for the integrity of the data and the accuracy of the data analysis. ARJ conducted and is responsible for the data analysis. Both authors read and approved the final manuscript.

\section{Acknowledgements}

MB was supported by a 2012 summer studentship grant from the Alberta Society of Infectious Disease; this sponsor had no role in any of the design and conduct of the study; collection, management, analysis, and interpretation of the data; and preparation, review, or approval of the manuscript. Part of this data was presented as an abstract at the American Thoracic Society Conference in May 2013.

\section{Author details}

${ }^{1}$ Faculty of Medicine and Dentistry, University of Alberta, Edmonton, Alberta T6G 2R3, Canada. ${ }^{2}$ Department of Pediatrics, 4-546 Edmonton Clinic Health Academy, University of Alberta, 1140587 Avenue, Edmonton, Alberta T6G 1C9, Canada.

Received: 5 May 2014 Accepted: 18 July 2014

Published: 29 July 2014

\section{References}

1. Horrobin DF: Modern biomedical research: an internally self-consistent universe with little contact with medical reality. Nat Rev Drug Discov 2003, 2:151-154.

2. Akhtar A: The Costs of Animal Experiments. In Animals and Public Health. Edited by Akhtar A. Houndmills: Macmillan; 2012:132-167.

3. West GB: The importance of quantitative systemic thinking in medicine. Lancet 2012, 379:1551-1559.

4. Van Regenmortel MHV: Reductionism and complexity in molecular biology. EMBO Rep 2004, 5:1016-1020.

5. Kilkenny C, Parsons N, Kadyszewski E, Festing MFW, Cuthill IC, Fry D, Hutton J, Altman DG: Survey of the quality of experimental design, statistical analysis and reporting of research using animals. PLoS One 2009, 4(11):e7284.

6. Ferdowsian HR, Beck N: Ethical and scientific considerations regarding animal testing and research. PLoS One 2011, 6(9):e24059

7. Sena E, van der Worp B, Howells D, Macleod M: How can we improve the preclinical development of drugs for stroke? Trends Neurosci 2007, 30:433-439.

8. Van der Worp HB, Howells DW, Sena ES, Porritt MJ, Rewell S, O'Collins V, Macleod MR: Can animal models of disease reliably inform human studies? PLoS Med 2010, 7(3):e1000245.

9. Landis SC, Amara SG, Asadullah K, Austin CP, Blumenstein R, Bradley EW, Crystal RG, Darnell RB, Ferrante RJ, Fillit H, Finkelstein R, Fisher M, Gendelman HE, Golub RM, Goudreau JL, Gross RA, Gubitz AK, Hesterlee SE, Howells DW, Huguenard J, Kelner K, Koroshetz W, Krainc D, Lazic SE, Levine MS, Macleod MR, McCall JM, Moxley RT, Narasimhand K, Noble LJ, et al: A call for transparent reporting to optimize the predictive value of preclinical research. Nature 2012, 490:187-191.

10. Dyson A, Singer M: Animal models of sepsis: why does preclinical efficacy fail to translate to the clinical setting. Crit Care Med 2009, 37(Suppl):S30-S37.

11. Opal SM, Patrozou E: Translational research in the development of nove sepsis therapeutics: logical deductive reasoning or mission impossible? Crit Care Med 2009, 37(Suppl):S10-S15.

12. Marshall JC, Deitch E, Moldawer LL, Opal S, Redl H, van der Poll T: Preclinical models of shock and sepsis: what can they tell us? Shock 2005, 24(Suppl 1):1-6.

13. Xiong Y, Mahmood A, Chopp M: Animal models of traumatic brain injury. Nat Rev Neurosci 2013, 14:128-142.

14. Reynolds PS: Twenty years after: do animal trials inform clinical resuscitation research? Resuscitation 2012, 83(1):16-17.

15. Akhtar AZ, Pippin JJ, Sandusky CB: Animal models of spinal cord injury: a review. Reviews Neurosciences 2009, 19:47-60.

16. Holmes AM, Solari R, Holgate ST: Animal models of asthma: value, limitations and opportunities for alternative approaches. Drug Discov Today 2011, 16(15-16):659-670.
17. Begley CG, Ellis LM: Drug development: raise standards for preclinical cancer research. Nature 2012, 483:531-533.

18. Pammolli F, Magazzini L, Riccaboni M: The productivity crisis in pharmaceutical R\&D. Nat Rev Drug Discov 2011, 10:428-438.

19. Sargeant JM, Elgie R, Valcour J, Saint-Onge J, Thompson A, Marcynuk P, Snedeker K: Methodological quality and completeness of reporting in clinical trials conducted in livestock species. Prev Vet Med 2009, 91:107-115.

20. Sargeant JM, Thompson A, Valcour J, Elgie R, Saint-Onge J, Marcynuk P, Snedeker K: Quality of reporting of clinical trials of dogs and cats and associations with treatment effects. J Vet Intern Med 2010, 24(1):44-50.

21. Bebarta V, Luyten $D$, Heard K: Emergency medicine and animal research: does use of randomization and blinding affect the results? Acad Emerg Med 2003, 10(6):684-687.

22. Lapchak PA, Zhang JH, Noble-Haeusslein L: RIGOR guidelines: escalating STAIR and STEPS for effective translational research. Trans/ Stroke Res 2013, 4(3):279-285.

23. Carlsson HE, Hagelin J, Hau J: Implementation of the "three R's" in biomedical research. Vet Record 2004, 154:467-470.

24. Fantzias J, Sena ES, Macleod MR, Slaman RA: Treatment of intracerebral hemorrhage in animal models: meta-analysis. Ann Neurol 2011, 69:389-399.

25. Baginskait J: Scientific Quality Issues in the Design and Reporting of Bioscience Research: A Systematic Study of Randomly Selected Original In Vitro, In Vivo and Clinical Study Articles Listed in the PubMed Database. In CAMARADES Monogr 2012. [http://www.dcn.ed.ac.uk/camarades/files/ Camarades\%20Monograph\%20201201.pdf]. Accessed 7 January 2014.

26. Vesterinen HM, Sena ES, Constant CF, Williams A, Chandran S, Macleod MR: Improving the translational hit of experimental treatments in MS. Mult Scler 2011, 17(6):647-657.

27. Festing MF, Altman DG: Guidelines for the design and statistical analysis of experiments using laboratory animals. ILAR J 2002, 43(4):244-258,

28. Kilkenny C, Browne WJ, Cuthill IC, Emerson M, Altman DG: Improving bioscience research reporting: the ARRIVE guidelines for reporting animal research. PLOS Biol 2010, 8(6):e1000412

29. Institute for Laboratory Animal Research: National Research Council: Guidance for the Description of Animal Research in Scientific Publications. Washington DC: National Academy of Sciences; 2011.

30. Canadian Council on Animal Care in Science: CCAC Guidelines on: Choosing an Appropriate Endpoint in Experiments Using Animals for Research, Teaching and Testing. Ottawa: Canadian Council on Animal Care; 1998. [http://www. ccac.ca/Documents/Standards/Guidelines/Appropriate_endpoint.pdf]. Accessed 3 May 2014.

31. Canadian Council on Animal Care in Science: CCAC Guidelines on: Animal use Protocol Review. Ottawa: Canadian Council on Animal Care; 1997. [http:// www.ccac.ca/Documents/Standards/Guidelines/Protocol_Review.pdf]. Accessed 3 May 2014.

32. Seok J, Warren S, Cuenca AG, Mindrinos MN, Baker HV, Xu W, Richards DR, McDonald-Smith GP, Gao H, Hennessy L, Finnerty CC, Lopez CM, Honari S, Moore EE, Minei JP, Cuschieri J, Bankey PE, Johnson JL, Sperry J, Nathens AB, Billiar TR, West MA, Geschke MG, Klein MB, Gamelli RL, Gibran NS, Brownstein BH, Miller-Graziano C, Calvano SE, Mason PH, et al: Genomic responses in mouse models poorly mimic human inflammatory diseases. Proc Natl Acad Sci U S A 2013, 110:3507-3512.

33. Odom DT, Dowell RD, Jacobsen ES, Gordon W, Maclsaac KD, Rolfe PA, Conboy CM, Gifford DK, Fraenkel E: Tissue-specific transcriptional regulation has diverged significantly between human and mouse. Nat Genet 2007, 39(6):730-732.

34. Romero IG, Ruvinsky I, Gilad Y: Comparative studies of gene expression and the evolution of gene regulation. Nat Rev Genet 2012, 13:505-516.

35. Brawand D, Soumillon M, Necsulea A, Julien P, Csardi G, Harrigan P, Weier M, Liechti A, Aximu-Petri A, Kircher M, Alberta FW, Zeller U, Khaitovich P, Grutzner F, Bergmann S, Nielsen R, Paabo S, Kaessmann H: The evolution of gene expression levels in mammalian organs. Nature 2011, 478:343-348.

36. Liao BY, Zhang J: Null mutations in human and mouse orthologs frequently result in different phenotypes. Proc Natl Acad Sci U S A 2008, 105:6987-6992.

37. Ecker JR, Bickmore WA, Barroso I, Pritchard JK, Gilad Y, Segal E: Forum: Genomics. ENCODE explained. Nature 2012, 489:52-55.

38. Warren HW, Fitting C, Hoff E, Adib-Conquy M, Beasley-Topliff EL, Tesini B, Liang X, Valentine C, Hellman J, Hayden D, Cavaillon JM: Resilience to bacterial infection: difference between species could be due to proteins in serum. J Infect Dis 2010, 201:223-232. 
39. Bara M, Joffe AR: The ethical dimension in published animal research in critical care: the public face of science. Crit Care 2014, 18(1):R15.

40. Scott S, Kranz JE, Cole J, Lincecum JM, Thompson K, Kelly N, Bostrom A, Theodoss J, Al-Nakhala BM, Vieira FG, Ramasubbu J, Heywood JA: Design, power, and interpretation of studies in the standard murine model of ALS. Amyotroph Lateral Scler 2008, 9:4-15.

41. Steward O, Popovich PG, Dietrich WD, Kleitman N: Replication and reproducibility in spinal cord injury research. Exp Neuro/ 2012, 233:597-605.

42. Rollin BE: Scientific autonomy and the 3Rs. Am J Bioeth 2009, 9(12):62-64.

43. Whittall H, Nuffield Council on Bioethics: Information on the 3Rs in animal research publications is crucial. Am J Bioeth 2009, 9(12):60-67.

44. Garrett JR: The Ethics of Animal Research: An Overview of the Debate. In The Ethics of Animal Research: Exploring the Controversy. Edited by Garrett JR. Cambridge, Massachusetts: MIT Press; 2012:1-16.

45. Rollin BE: Animal research: a moral science. EMBO Rep 2007, 8(6):521-525.

46. Kmietowicz Z: Researchers promise to be more open about use of animals in their work. BMJ 2012, 345:e7101.

47. MORI Ipsos: Views on Animal Experimentation. UK: Department for Business Innovation \& Skills; 2009

48. Goodman JR, Borch CA, Cherry E: Mounting opposition to vivisection. Contexts 2012, 11:68-69.

49. Poole T: Happy animals make good science. Lab Animals 1997, 31:116-124.

50. Balcombe JP: Laboratory environments and rodents' behavioral needs: a review. Lab Anim 2006, 40:217-235.

51. Tsilidis KK, Panagiotou OA, Sena ES, Aretouli E, Evangelou E, Howells DW, Salman RA, Macleod MR, loannidis JPA: Evaluation of excess significance bias in animal studies of neurological diseases. PLoS Biol 2013, 11(7):e1001609.

52. Savović J, Jones HE, Altman DG, Harris RJ, Jüni P, Pildal J, Als-Nielsen B, Balk EM, Gluud C, Gluud LL, loannidis JPA, Schulz KF, Beynon R, Welton NJ, Wood L, Moher D, Deeks JJ, Sterne JAC: Influence of reported study design characteristics on intervention effect estimates from randomized controlled trials. Ann Internal Med 2012, 157(6):429-438.

53. Hrobjartsson A, Thomsen AS, Emanuelsson F, Tendal B, Hilden J, Boutron I, Ravaud P, Brorson S: Observer bias in randomized controlled trials with measurement scale outcomes: a systematic review of trials with both blinded and nonblinded assessors. CMAJ 2013, 185(4):e201-e211.

54. Baker D, Lidster K, Sottomayor A, Amor S: Two years later: journals are not yet enforcing the ARRIVE guidelines on reporting standards for pre-clinical animal studies. PLoS Biol 2014, 12(1):e1001756.

55. Knight A: The Costs and Benefits of Animal Experiments. Houndmills: Macmillan; 2013

56. Shanks N, Greek R, Greek J: Are animal models predictive for humans? Philos Ethics Humanities Med 2009, 4:2

57. Greek R, Rice MJ: Animal models and conserved processes. Theor Biol Med Model 2012, 9:40.

58. Dreyfuss D, Saumon G: Ventilator-induced lung injury. Am J Respir Crit Care Med 1998, 157:294-323.

59. Tonelli AR, Zein J, Adams J, loannidis JPA: Effects of interventions on survival in ARDS: an umbrella review of 159 published RTs and 29 MAs. Intensive Care Med 2014, 40(6):769-787.

60. loannidis JPA: Why most published research findings are false. PLOS Med 2005, 2(8):e124.

61. Simmons JP, Nelson LD, Simonsohn U: False-positive psychology: undisclosed flexibility in data collection and analysis allows presenting anything as significant. Psych Sci 2011, 22(11):1359-1366.

62. Nuzzo R: Statistical errors. Nature 2014, 506:150-152

63. Goodman SN: Toward evidence-based medical statistics. 1: the $p$ value fallacy. Ann Intern Med 1999, 130:995-1004.

64. Goodman SN: Of p-values and Bayes: a modest proposal. Epidemiology 2001, 12(3):295-297.

65. Goodman SN: Toward evidence-based medical statistics. 2: the Bayes factor. Ann Intern Med 1999, 130:1005-1013.
66. Johnson VE: Revised standards for statistical evidence. Proc Natl Acad Sci U S A 2013, 110(48):19313-19317.

67. Osborne NJ, Payne D, Newman ML: Journal editorial policies, animal welfare, and the 3Rs. Am J Bioethics 2009, 9:55-59.

68. Marusic A: Can journal editors police animal welfare? Am J Bioethics 2009, 9:66-67.

doi:10.1186/s13613-014-0026-8

Cite this article as: Bara and Joffe: The methodological quality of animal research in critical care: the public face of science. Annals of Intensive Care 2014 4:26

\section{Submit your manuscript to a SpringerOpen ${ }^{\odot}$ journal and benefit from:}

- Convenient online submission

- Rigorous peer review

- Immediate publication on acceptance

- Open access: articles freely available online

- High visibility within the field

- Retaining the copyright to your article

Submit your next manuscript at $>$ springeropen.com 